\title{
A CONSTRUCÃO DA NOTÍCIA E O TELEJORNALISMO APÓCRIFO: uma investigação sobre a agenda dos acontecimentos ${ }^{1}$
}

\section{The newsmaking and apocryphal television news bulletin: an investigation on events agenda}

\author{
ANA PAULA GOULART DE ANDRADE ${ }^{2}$ \\ SANDRO TÔRRES DE AZEVEDO ${ }^{3}$
}

Resumo: Cada vez mais, as imagens de vídeos amadores e de câmeras de vigilância têm comparecido na narrativa telejornalística como elementos de construção da notícia. Assim, esse trabalho se propõe a investigar a questão do agendamento dos acontecimentos que, por hipótese, são pontuados pelas imagens produzidas por agentes exteriores à empresa jornalística - e que temos conceituado como "telejornalismo apócrifo". Numa perspectiva ensaística, a pesquisa aponta para novos aspectos da comunicação jornalística diante da popularização dos dispositivos digitais e, essencialmente, do fazer jornalístico no contexto da cultura contemporânea marcada pelas novas tecnologias interativas de informação e comunicação.

Palavras-chave: Telejornalismo apócrifo; construção da notícia; agendamento.

Abstract: Increasingly, images from amateur videos and from surveillance cameras have been part of the news narrative as elements of the newsmaking process. Therefore, this paper purposes to investigate the question on agenda-setting issues that, hypothetically, are pointed out by images produced by those ones outside the news firms - and

\footnotetext{
${ }^{1}$ Outra versão desse trabalho foi apresentada no $9^{\circ}$ Encontro Nacional de Pesquisadores em Jornalismo SBPJor, realizado na ECO/UFRJ, em novembro de 2011. A referida versão foi premiada na categoria Artigos Científicos do V Concurso Interno Nacional de Produções Científicas e Projetos de Extensão, realizado pelo Grupo Estácio.

${ }^{2}$ Mestranda em Comunicação pela Pontifícia Universidade Católica do Rio de Janeiro PUC-Rio; especialista em Telejornalismo pela UNESA; graduada em Comunicação Social - Jornalismo pela UNESA; jornalista, editora de texto da Rede Record de Televisão e professora do curso de Comunicação Social Jornalismo da UNESA; membro da Rede de Pesquisa em Telejornalismo da SBPJor.E-mail: goulartdeandrade@gmail.com.

${ }^{3}$ Doutorando em Estudos de Linguagem pela UFF; mestre em Comunicação e Cultura pela UFRJ; graduado em Comunicação Social - Publicidade e Propaganda pela UFF; publicitário e professor dos cursos de Comunicação Social da UNESA, da UVA e da FACHA; vice-líder do ReC (Grupo de Pesquisa em Retórica do Consumo - UFF) e membro do SeDi (Grupo de Pesquisa em Semiótica e Discurso - UFF).

E-mail: sandrotorres.com@gmail.com.
} 
conceptualized as "apocryphal television news bulletin". Under an essayistic perspective, this paper shows new aspects of journalistic communication facing digital devices and, substantially, the process of making journalism in contemporary culture, by using new interactive technologies on information and communication.

Key-Words: apocryphal television news bulletin; newsmaking; agenda-setting. Introdução

A cena telejornalística contemporânea tem sido alimentada de forma progressivamente abundante com imagens capturadas por câmeras amadoras e, mais ainda, por circuitos de vigilância. No entanto, esse trabalho pleiteia que a atenção a isso deve não só superar o senso comum que nota os flagrantes contidos nessas imagens, quanto, academicamente, ultrapassar o determinismo tecnológico que podem inspirar, para alcançar uma perspectiva mais ampla dos modos e processos que envolvem o Jornalismo no século XXI e, especificamente, aspectos relacionados à construção da notícia e ao agendamento dos acontecimentos.

De antemão, o fato de o noticiário televisivo estar marcado pela presença corriqueira de imagens capturadas por instâncias externas às empresas jornalísticas se integra ao entendimento de que o Jornalismo, bem como as mais diversas áreas da Comunicação Social, vem sofrendo tanto o impacto da popularização dos dispositivos digitais, quanto de seus efeitos. Além de essa afirmação coadunar com a prerrogativa de que a Cibercultura é mais do que uma questão tecnológica, mas sim uma atitude da sociedade contemporânea, ela enseja novos olhares sobre o jogo social do qual o Telejornalismo participa e que envolve, de um lado, a tecnologia midiática e, de outro, a arena midiática.

Dando continuidade a pesquisa que trata e postula a ideia de Telejornalismo Apócrifo (ver ANDRADE, 2010 e ANDRADE \& AZEVEDO, 2010), o presente artigo se volta, então, para a hipótese de que o agendamento da notícia passa a sofrer a interferência de agentes externos ao jornalismo, caracterizando um diálogo (mais ou menos evidente) entre a produção midiática e outras instâncias sociais, na medida em que essas últimas passam a se configurar como cedentes de matérias-primas (conteúdo audiovisu- 


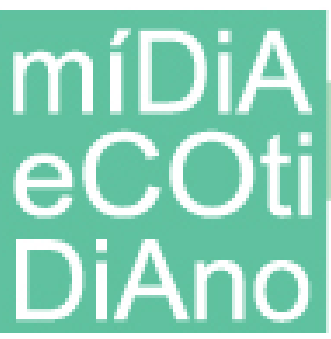

al originados por câmeras amadoras ou de segurança) que vão constituir diversos produtos jornalísticos.

Outrossim, na esteira da reflexão teórica sobre o Jornalismo, a qual essa pesquisa enfim se anela, conceitos como os de: Newsmaking de Mauro Wolf (2003), mediadores públicos de Alfredo Vizeu (2010), pseudo-acontecimentos de Daniel Boorsting (1961), além da Teoria Construtivista apresentada por Nelson Traquina (2004), serão, então, abordados com o intuito de lançar mais luz sobre a questão e elencar, assim, os constructos necessários para a elaboração da proposição que ora se faz.

\section{Reconhecendo o objeto: o telejornalismo apócrifo}

O ritmo desenfreado de inovações tecnológicas que se tem experimentado nas últimas décadas trouxe como consequência a inevitável popularização dos mais diversos tipos de dispositivos, dentre os quais figuram os de captura de imagens. Se, antigamente, os recursos tecnológicos de produção audiovisual eram quase que exclusividade das emissoras de televisão e estúdios cinematográficos (pouquíssimas pessoas alheias ao fazer profissional dispunham de tais aparatos), atualmente, esses recursos alcançaram praticamente todos os espectros sociais, na forma de filmadoras amadoras, câmeras de circuito interno, câmeras fotográficas e celulares dotados de recursos audiovisuais, webcams etc., que servem aos mais diversos propósitos do cidadão comum, mas que também operam em serviços de segurança para empresas, condomínios, shopping centers e até ao governo, na forma de sistemas de controle de tráfego e vigilância dos espaços públicos, por exemplo.

Mais do que resultar numa produção exponencial de conteúdos audiovisuais, o fato observado vem ocasionando um número avassalador de flagrantes das cenas do cotidiano, de tal sorte que praticamente todo e qualquer acontecimento tem sido capturado e registrado por algum tipo de dispositivo de visibilidade, numa situação bastante 


\section{eCD DiAno}

análoga ao que imaginou George Orwell $^{4}$ (1998) e muito além do panóptico analisado por Foucault ${ }^{5}$ (2001).

Não é à toa, pois, que os sites de compartilhamento de vídeos, por exemplo, o Youtube, tem logrado grande sucesso de audiência. Parece que a sociedade como um todo tem se hiperexcitado com a multiplicidade de vídeos disponíveis para apreciação, obedecendo às mais diversas motivações, desde o entretenimento até a informação.

Assim é que, no embalo das circunstâncias, essas mesmas imagens têm figurado no conteúdo das grades de programação da TV, inclusive como elementos constitutivos dos telejornais. Daí, uma infinidade de conteúdos que originariamente não estariam comprometidos com a noticiabilidade, tem sido utilizada em demasia no resultado das edições de produtos telejornalísticos.

Dessa forma, o olhar do indivíduo comum tem coabitado a cena jornalística, concretizando o que se tem chamado de "jornalismo participativo”, no qual se evidencia um espaço de representação que outrora era exclusivamente circunscrito às redações dos veículos.

Talvez seja esse um dos motivos pelos quais a época de predominância do oficialismo das fontes, em que a voz dos cidadãos pouco recebia atenção, deu lugar a uma relação dialógica com um jornalismo que, além de dar voz, também se vale de textos, imagens e vídeos produzidos por esse cidadão. Dessa forma, configuram-se novas maneiras de relação entre as distintas mídias e suas audiências, novas formas e processos de comunicação (AMORIM, 2009, p.03).

Esse fenômeno se integra a realidade da cultura contemporânea marcada pelas novas tecnologias de informação e comunicação, na qual cada um pode ser "produtor, criador, compositor, montador, apresentador, difusor de seus próprios conteúdos” (SANTAELLA, 2004, p.82), e, assim, pode-se constatar que a televisão vem sentido os

\footnotetext{
${ }^{4}$ George Orwell, escritor e jornalista inglês, foi autor do livro de fiç̧ão científica "1984", escrito em 1948, no qual imaginou uma sociedade dominada por um governo totalitário que vigiava todos os cidadãos através de sistemas onipresentes de monitoramento por câmeras.

${ }^{5}$ Michel Foucault, filósofo francês, em sua obra "Vigiar e punir: nascimento da prisão", escrita em 1975, analisou o panóptico - um modelo arquitetônico de sistema prisional idealizado pelo filósofo e jurista inglês Jeremy Bentham, no qual um vigilante poderia espreitar todos os prisioneiros da penitenciária sem que os mesmos pudessem saber quando ou se estavam sendo observados, decorrendo daí uma série de processos de investimento e poder e, consequentemente, de influência sobre o comportamento dos cativos.
} 


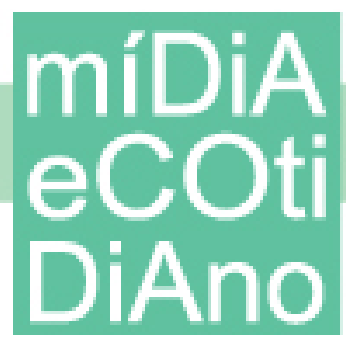

efeitos da virada de uma sociedade determinada pela distribuição piramidal de conteúdos para uma marcada pela distribuição reticular (idem, ibidem).

Destarte, pode-se observar que as novas tecnologias têm contribuído a cada dia para a construção de novos modos de interpretação dos fatos cotidianos a partir de perspectivas construídas por dispositivos audiovisuais operados por "leigos”, que resultam no que se pode considerar um “telejornalismo apócrifo”: aquele que se origina (ou flerta) no exterior dos cânones tradicionais do fazer jornalístico.

Assim, boa parte do noticiário é preenchida por diversas imagens cedidas pelo cidadão comum, pela polícia local, pelas câmeras de controle de tráfego etc., comumente cobertas por locuções em off ou mesmo por ancoragem do apresentador ao vivo.

\section{O telejornalismo apócrifo na construção social da realidade}

O telejornalismo apócrifo tem se tornado uma prática contumaz na composição dos noticiários televisivos. Talvez, a dinâmica das imagens apócrifas seja mais sedutora do que a transmissão de informações que, mesmo muito relevantes, se restrinjam a cenas "estáticas" de apresentadores narrando notas secas ${ }^{6}$. Além de ilustrar a notícia, a sequência de imagens invariavelmente explora, então, o movimento visual requerido pelo telespectador ávido por estímulos sensoriais mais intensos, como é de senso comum na atualidade - inclusive, para corroborar a máxima corrente nas redações telejornalísticas que diz que “TV é imagem”.

A título de exemplo, vejam-se os espaços nos telejornais locais das grandes metrópoles destinados a "serviços", em particular sobre as indicações do tráfego de veículos nas principais avenidas. Tornou-se natural o link ao vivo com as imagens captadas por câmeras de órgãos públicos de observação do trânsito na cidade. O apresentador/âncora do telejornal narra a cena, informando sobre eventuais fatos, abordando

\footnotetext{
${ }^{6}$ Segundo Vera Íris Paternostro (1999), nota seca (ou nota pelada) refere-se a informação lida pelo apresentador sem cobertura de imagem. Atualmente, as notas secas - aposta-se que, muito em parte, justamente pela alta frequência do jornalismo apócrifo - tem praticamente se relegado a apresentação de notícias relevantes de última hora.
} 


\section{míDiA

questões relacionadas aos fluxos urbanos. Certamente, dessa forma, esse tipo de produto jornalístico ganha muito mais expressão sensória e, consequentemente, cativa mais a atenção dos telespectadores, obviamente com vistas à audiência.

Assim, o telejornalismo apócrifo, enquanto prática cada vez mais costumeira transforma-se em mais um elemento de inspiração para se investigar os desafios impostos à atividade jornalística no mundo contemporâneo, dada a circulação excessiva e flutuante de informações num cenário digital que obriga o jornalista a repensar o seu papel e a sua forma de atuação no processo produtivo, sobretudo nos telejornais. Contribuir nessa direção é o que se intenta nas linhas em sequência.

A princípio, um ponto a se destacar é que as imagens apócrifas já fazem parte do escopo da realidade construída pelo imaginário do público espectador, já que, como visto acima, ele mesmo já manuseia com naturalidade e intencionalidades os dispositivos amadores, tanto quanto já se apropria das mais diversas imagens depositadas em sites de compartilhamento de vídeos da internet. Essa prerrogativa é o que viabiliza as imagens apócrifas serem acionadas pelos telejornais como objetos naturais de composição de narrativas a serem veiculadas.

Berger e Luckmann (2003), ao analisarem o jornalismo como dispositivos de construção social da realidade admitem um processo dialético entre a realidade objetiva e a subjetiva. A partir da releitura da sociologia do conhecimento, os autores levam em consideração a opinião do senso comum como parte constituinte da realidade rotineira. Para eles a vida cotidiana é dominada por motivos pragmáticos e daí ocupa um lugar eminente no acervo social do conhecimento. "O capital social do conhecimento fornece meios de integrar elementos descontínuos (...). 'Tudo aquilo que todo mundo sabe’ tem sua própria lógica e a mesma lógica pode ser aplicada para ordenar várias outras coisas” (BERGER \& LUCKMANN, 2003, P.65). Dessa forma, tem-se aí a possibilidade dos eventuais acervos de imagens apócrifas coincidirem em significação com representações já presentes no repertório dos telespectadores e, por isso, poderem figurar na narrativa televisiva sem ruídos ou dissonâncias simbólicas.

Mais ainda, a narrativa jornalística explora a percepção constituída pela audiência que infere valor de verdade às imagens apócrifas e, dessa maneira, esvazia-se 


\section{ecd DiAno}

toda e qualquer ideia de opinião ou ponto-de-vista emitido pela empresa jornalística. $\mathrm{O}$ efeito de verdade surge exatamente da sensação de que a imagem cedida, independente da fonte, é descolada da linha editorial do veículo de comunicação - já que foi capturada por sujeitos alheios ao fazer jornalístico, parece ser sincera. Interessante destacar que a instituição "redação jornalística” atribui uma construção discursiva de independência e/ou imparcialidade na captação dos fatos contidos nas imagens "leigas”, porque foi, a princípio, livre de negociações inerentes ao fazer jornalístico, que incluem o planejamento editorial (esse sim, calcado na lógica de versões).

Mais que isso, a imagem cedida força o telespectador a ocupar o lugar do olho do observador que efetivamente testemunhou o facto, driblando qualquer outro elemento que compareça na narrativa como um todo.

Assim, se pela ótica da Teoria Construcionista, as notícias ajudam a produzir uma determinada realidade, o telejornalismo apócrifo cumpre com essa lógica de forma facilitada, beneficiado pela presunção de verdade que já se encontrava anteriormente colada na percepção estabelecida por todos sobre as imagens amadoras.

Nessa teia de "facticidade" autores como Molotch e Lester (1971), Hall et al. (1999) e Tuchman (1993), também compartilham o pensamento de que a imprensa funciona como um instrumento de representação social da realidade e de que uma notícia é uma história, logo, uma realidade construída. Stuart Hall, ao analisar o que chamou de mapas do significado, compreende o mundo como um lugar de conflitos encharcado de imprevisibilidade e volatilidade.

Mas não se deve permitir que tais acontecimentos permaneçam no limbo do aleatório - devem ser trazidos aos horizontes do significativo. (...) A identificação social, classificação e contextualização de acontecimentos noticiosos em termos destes quadros de referência de fundo constitui o processo fundamental através do qual os media tornam inteligível a leitores e espectadores o mundo a que fazem referência. (HALL et al., 1999, p.226).

Em verdade, Hall et al. (idem, ibidem), ainda através do paradigma construcionista, aponta para o processo de enquadramento jornalístico entendido aqui como a narrativa usada para determinar um acontecimento, a escolha de um assunto ou outro. Carey (1986) também concorda que o acontecimento, ao provocar narrativas sobre ele 


\section{ecd DiAno}

mesmo, contribui para a construção da realidade. Todo esse processo que transforma matéria-prima [os acontecimentos] em um produto jornalístico [as notícias] atende aos requisitos requeridos para que o fato seja agendado (seja pela ótica dos órgãos de informação, seja pela dos profissionais das redações). Mauro Wolf filia-se a este ponto de vista: “as notícias são aquilo que os jornalistas definem como tal” (WOLF, 2003, p.190).

\section{$O$ agente externo e $\mathrm{o}$ agendamento}

Apesar de o telejornalismo apócrifo parecer estar submetido às mesmas lógicas que qualquer conteúdo noticioso (porque se utiliza de ferramentas semelhantes de apuração na medida em que o jornalista - entendido como um agente social comum determina o enquadramento necessário para um acontecimento, enfatizado pela ânsia de sensações), o tratamento do recorte/enquadramento/tema do acontecimento é diferente, não só pela apuração, mas também pela trajetória do processo de construção da notícia, até porque o jornalista, ao se apropriar de imagens apócrifas, se utiliza de material captado por dispositivos audiovisuais tecnológicos manuseados por 'leigos' e que surge no exterior dos cânones do Jornalismo. Por conta disso, a produção de imagens que vão ilustrar o acontecimento a ser noticiado é anterior à produção da pauta do mesmo acontecimento, o que caracteriza uma inversão dos modos tradicionais do fazer jornalístico. Por conseguinte, vale a reflexão cuidadosa sobre o agendamento ainda deste mesmo acontecimento.

Segundo Wolf (2003, p.188-244), a hipótese de agenda-setting sustenta que as pessoas tendem a absorver ou expurgar os seus próprios conhecimentos de acordo com o que mídia absorve ou expurga do seu próprio conteúdo. Sendo assim, a mídia define os assuntos a serem tratados e discutidos pelo público em um determinado dia, de acordo com os fatos abordados, escolhidos ou, ainda, enquadrados.

Os estudos sobre Newsmaking contribuem para o entendimento das notícias nos modelos que são ofertados à sociedade. Mauro Wolf também elenca critérios de noticiabilidade que determinam um acontecimento: "Determina-se, assim, um conjunto 
de critérios de relevância, que definem a noticiabilidade (newswortthines) de cada evento, ou seja, sua ‘aptidão’ para ser transformado em notícia (...). Sendo assim, a noticiabilidade está estritamente ligada aos processos que padronizam e tornam rotineiras as práticas de produção” (WOLF, 2003, p.195).

Por esse caminho, em se tratando do telejornalismo apócrifo, o agendamento de notícias sofre intervenções por parte também de quem cede as imagens. Sob a égide do que se tem chamado de "jornalismo participativo", o cedente passa a coabitar um espaço antes restrito às empresas jornalísticas (e seus prepostos), que decidiam o que era notícia. Agora, esse agente externo também define um enquadramento, configurado em uma linguagem "bruta”, mas que conta uma história. E, diante das buscas sôfregas por interatividade, próprias dos produtos midiáticos que se contextualizam na Web 2.0, essa "participação" cada vez mais tem se fortalecido nas redações, principalmente televisivas, que anseiam por matérias-primas que contenham valor-notícia e, portanto, preencham as grades de programação. Em troca, o produtor do telejornalismo apócrifo se reconhece potente na tomada de decisões do fazer jornalístico.

Na medida em que esse agente externo se envolve na escolha de enquadramentos, o conteúdo que lhe pertencia (as imagens) ganha dimensão e significado cultural de "Notícia” - torna-se um conteúdo jornalístico distribuído na forma de produto midiático no padrão do discurso que é chancelado pela empresa jornalística de TV.

Para Alfredo Vizeu, esses novos agentes que atuam como co-produtores da notícia são chamados de "mediadores públicos”, são cidadãos comuns que dialogam com o campo do Jornalismo, contribuindo para a agenda dos meios e para a produção de notícias. No entanto, salienta o risco desses agentes que contribuem na construção de notícias serem considerados jornalistas: "Não vemos essas pessoas como jornalistas que representam uma profissão e que têm que coletar fatos, classificá-los, sistematizá-los, hierarquizá-los, checá-los a bem não só da credibilidade, mas da ética pública. (...) consideramos essas pessoas o que podemos chamar de 'mediadores públicos'” (VIZEU et al., 2010, p.6).

Ao analisar o Telejornalismo como lugar de referência através dos mediadores e espaços públicos, Vizeu considera também os tipos de atores que participam da 


\section{ecd DiAno}

construção de sentido no espaço público, cujo crescimento tem sido progressivo em função da cada vez mais fácil acesso à mídia.

Isso vai ao encontro de Habermas, que já havia observado que a conquista de influência política obtida na comunicação pública encontra fundamento "em última instância, na ressonância ou, mais precisamente, no assentimento de um público de leigos que possui os mesmos direitos” (HABERMAS, 1997, p.96).

Dessa forma, é conferida uma autoridade ao público porque o poder de persuasão é decisivo na definição de sentido sobre os temas considerados relevantes para configurar na pauta de discussão. E é justamente essa autoridade na decisão do agendamento o ápice desta pesquisa, considerando o telejornalismo com um gênero de influência e que, portanto, exerce um papel determinante na formação de sentido e na construção social da realidade, conforme já citado anteriormente.

\section{O que vem primeiro, a pauta ou a imagem?}

Para ilustrar essa questão sobre o agendamento, veja-se o exemplo da cobertura jornalística dada pela TV Record/Rio a uma série de roubos ocorrida no bairro do Catete, zona Sul do Rio de Janeiro. Os produtos jornalísticos apresentados em telejornais variados da emissora ${ }^{7}$ davam conta de "onda” de assaltos a lojas diversas que tinham um denominador comum: possuíam câmeras de vigilância que eram operadas pela mesma empresa de segurança. Possivelmente, tais eventos nunca seriam noticiados em telejornais se a central de segurança não tivesse acessado a emissora para oferecer as imagens dos flagrantes.

A “força” dos conteúdos dos vídeos apresentados conferiu valor-notícia aos fatos, elevando-os ao status de acontecimentos e, portanto, pautáveis pela mídia - a quem cabia a exclusividade na decisão do que é ou não notícia. O exemplo em questão serve para a constatação empírica do que essa pesquisa se propõe a discutir: os agentes

\footnotetext{
7 Alguns VTs podem ser conferidos em http://videos.r7.com/flagrantes-cameras-registram-assaltos-alojas-em-bairro-da-zona-sul-do-rio/idmedia/4dda6b16fc9b8e6a021b19d6.html, ou em http://videos.r7.com/bandido-rouba-deposito-de-gelo-no-rio-enquanto-o-dono-do-estabelecimentodorme/idmedia/4dda56c4b51a3c018f445b99.html.
} 


\section{míDiA

externos agora participam efetivamente do agendamento de notícias. E as imagens apócrifas funcionaram justamente como o passaporte do agente externo para a participação na produção do noticiário televisivo.

Note-se: as imagens foram produzidas antes mesmo que a pauta pudesse ser pensada. A matéria jornalística se origina de um produto "pré-fabricado”.

Ainda, as imagens provocam estímulos sensoriais, causam impacto junto aos telespectadores, promovendo efeitos hipnóticos suficientes para sustentar a audiência da programação - sucesso que notas secas dificilmente lograriam.

Também, as imagens das câmeras de vigilância falam por si só, isto é, fazem parte de uma realidade construída - "aquilo que todo mundo sabe” promove o agendamento: o bairro do Catete está violento; lugares violentos têm sido monitorados por câmeras de vigilância; os bandidos estão cada vez mais ousados; e por aí vai.

Além do mais, uma sonora que contivesse o depoimento de uma das vítimas ou a uma entrevista a um agente de segurança não seria tão eficaz para conferir efeito de verdade sobre os fatos narrados. Isso se dá porque o jornalismo apócrifo, como pleiteado mais acima, é percebido pelo público revestido de uma aura de independência e imparcialidade porque parece (e talvez seja) isento.

Enfim, o percurso da construção da notícia analisado rompe com a rotina da instituição jornalística, despadronizando as práticas de produção que até então se mostravam fiéis ao tradicionalismo da agenda-setting.

\section{Conclusão}

Vale ainda nesse trabalho a reflexão sobre o conceito de pseudoacontecimentos (ou pseudo-eventos), de Daniel Boorstin (apud SERRANO, 2003). O termo traduz a invenção de eventos fabricados para serem noticiados enquanto acontecimentos midiáticos.

Quando uma notícia tem certo "valor midiático”, mas ainda assim não encontra espaço na mídia, são criados os pseudo-acontecimentos, muitas vezes construídos por quem tem algum interesse de tornar “obrigatória” a veiculação de determinado 


\section{ecc DiAno}

assunto. Estrela Serrano, estudando Boorstin, afirma que um exemplo de pseudoacontecimento é a fuga de informação: “A ‘fuga’ começou como uma prática ocasional de uma fonte oficial transmitir informação confidencial a alguns jornalistas. Hoje, tornou-se uma maneira institucional de transmitir informação. A sua ambigüidade e o ambiente de confidência e intriga em que se processa criam um clima de confiança entre jornalistas e fontes” (idem, p.8).

Entretanto, e para finalizar, faz-se necessário tomar o cuidado de relativizar possíveis conclusões apressadas, que tendem a condenar ou absolver determinada prática em foco, principalmente quando a questão transita pelo contexto da popularização dos dispositivos digitais ou da cultura contemporânea marcada pelas novas tecnologias de informação e comunicação. Assim, é oportuno recorrer aos apontamentos feitos por Francisco Rüdiger (2011), que identifica três correntes comuns de linhas de pensamento na Cibercultura, a saber: tecnófilos, tecnófobos e cibercriticistas.

Parece, pois, prudente não filiar as análises pontuadas nesse artigo ao lado dos tecnófilos: normalmente profissionais e pesquisadores da Comunicação que tendem a olhar os fenômenos que decorrem do surgimento de novas tecnologias com entusiasmo excessivo, ao ponto de defenderem com ardor (ou populismo) que há uma revolução cultural em curso, atribuindo-lhes virtudes morais e políticas.

\footnotetext{
Segundo esses tecnófilos todos estamos, portanto, em meio a uma revolução cultural, embasada na expansão das mídias digitais interativas, que tende a reduzir o poder das empresas multimídia de maior porte sobre o público e anuncia o fim ou o declínio da autoridade dos especialistas em cultura e comunicação. (...) O público determina a forma e o conteúdo do meio, estrutura e controla a comunicação. (...) Conferindo maior poder ao indivíduo, relativamente às organizações verticais e centralizadas dos tempos da velha mídia e das indústrias de cultura (RÜDIGER, 2011, p.31-32).
}

Pensando no telejornalismo apócrifo, ser tecnófilo implicaria supor que a mídia é um mal a ser contido ou dominado - e não há indícios de que existe alguma intencionalidade política ou moral por parte dos agentes sociais que captam e oferecem imagens amadoras.

Menos sedutora ainda é a posição dos tecnófobos: conservadores midiáticos, literários e intelectuais de formação mais tradicional, que escarnecem dos efeitos da 


\section{ecd DiAno}

\section{PPGMC}

popularização das tecnologias de comunicação, que quase “demonizam” as novas práticas que tem se manifestado nos processos comunicacionais contemporâneos.

A Web 2.0, em suma, estimula uma democratização que solapa a verdade, esvazia o discurso cívico e rebaixa os talentos (...). O fato grave seria que, por meio da nova mídia, estimula-se um circuito narcisista em que as pessoas se esquecem de que a procura as informações que apenas refletem suas crenças e opiniões, via de regra, não representa um avanço cognitivo, mas a perda do contato com outras, mias neutras, objetivas e diferentes, as únicas que favorecem a conversa esclarecida ou o debate fundamentado informado sobre qualquer assunto (idem, p.35).

Rüdiger, nesse caso, ainda lembra Andrew Keen, que sugere que a mídia tradicional deve ser defendida do culto ao amador.

Conforme foi abordado mais acima nessa pesquisa, o jornalismo apócrifo intui, ao contrário, que as empresas jornalísticas apreciam a participação dos agentes externos e imagens leigas, já que, inclusive, ajudam a preencher a programação. Em alguns casos, pode-se dizer, até estimula, como é o caso de iniciativas do tipo “envie seu vídeo”, evidenciando uma estratégia empresarial.

Mais interessante, pelo menos a princípio, é seguir pelo caminho do cibercriticismo: terceira tendência abordada por Rüdiger que inclui aqueles que buscam identificar potencialidades, problemas e desafios que os sujeitos sociais enfrentam na atualidade diante da popularização dos dispositivos tecnológicos de informação e comunicação, posicionando-se criticamente sobre os novos aspectos que decorrem dela.

Assim, não se trata, portanto e enfim, de encerrar essa pesquisa rotulando o jornalismo apócrifo como bom ou ruim. É uma tendência que se observa franca e que a pesquisa em questão, longe de findar a discussão sobre o tema, compreende que o seu objeto ainda se encontra em processo de acomodação.

\section{Referências}

AMORIM, Lidiane Ramirez de. (Tele)jornalismo participativo: novos olhares sobre a notícia de TV. In: Anais do XXXII Congresso Brasileiro de Ciências da Comunicação. São Paulo: Intercom, 2009.

ANDRADE, Ana Paula Goulart de. Telejornalismo apócrifo: imagens de câmeras de vigilância e vídeos amadores na construção da narrativa telejornalística. In: Anais do XXXIII Congresso Brasileiro de Ciências da Comunicação. São Paulo: Intercom, 2010. 
ANDRADE, Ana Paula Goulart de \& AZEVEDO, Sandro Tôrres. Imagens cedidas e a narrativa jornalística na TV: o telejornalismo apócrifo e a dupla performance. In: Anais do VIII Encontro Nacional de Pesquisadores em Jornalismo. São Luís: CD-Rom, 2010.

BERGER, Peter: LUCKMANN, Thomas. A construção social da realidade. Petrópolis: Vozes, 2003.

FOUCAULT, Michel. Vigiar e Punir: nascimento da prisão. 24. ed. Petrópolis: Vozes, 2001.

HABERMAS, Jurgen. Direito e democracia entre facticidade e validade. Vol. 1. São Paulo: Tempo Brasileiro, 1997.

HALL, Stuart et al. A produção social das notícias. In: TRAQUINA, Nelson. Jornalismo: questões, teorias e "estórias". Lisboa: Vega Editoria, 1999.

MOLOTCH, Harvey; LESTER, Marilyn. As noticias como procedimento intencional. In: TRAQUINA, Nelson. Jornalismo: questões, teorias e "estórias". Lisboa: Vega Editoria, 1999.

ORWELL, George. 1984. São Paulo: Companhia Editora Nacional, 1998.

PARTENOSTRO, Vera Íris. O texto na TV: manual de telejornalismo. Rio de Janeiro: Campus, 1999.

RÜDIGER, Francisco. As teorias da cibercultura: perspectivas, questões e autores. Porto Alegre: Sulina, 2011.

SANTAELLA, Lucia. Culturas e artes do pós-humano: da cultura das mídias à cibercultura. 2.ed. São Paulo: Paulus, 2004.

SERRANO, Estrela. Jornalismo e elites do poder. In: Ciberlegenda - Revista do Programa de Pós-graduação em Comunicação da Universidade Federal Fluminense, $\mathrm{n}^{\circ}$ 12, 2003. <http://www.uff.br/ciberlegenda/ojs/index.php/revista/article/view/272/157>

TRAQUINA, Nelson. Teorias do jornalismo. Florianópolis: Insular, 2004.

TUCHMAN, Gaye. A objetividade como ritual estratégico. In: TRAQUINA, Nelson. Jornalismo: questões, teorias e "estórias”. Lisboa: Veja Editoria, 1999.

VIZEU, Alfredo; SIQUEIRA, Fabiana \& ROCHA, Heitor. Telejornalismo: da audiência presumida aos co-produtores da notícia. In: Anais do XXXIII Congresso Brasileiro de Ciências da Comunicação. São Paulo: Intercom, 2010.

WOLF, Mauro. O newsmaking: critérios de importância. In: Teorias da comunicação. Lisboa: Presença, 2003. 